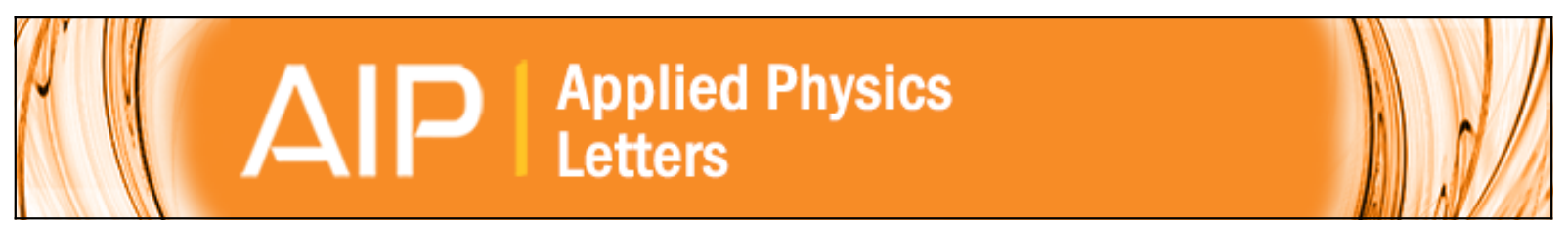

\title{
Electronic passivation of silicon surfaces by thin films of atomic layer deposited gallium oxide
}

T. G. Allen and A. Cuevas

Citation: Applied Physics Letters 105, 031601 (2014); doi: 10.1063/1.4890737

View online: http://dx.doi.org/10.1063/1.4890737

View Table of Contents: http://scitation.aip.org/content/aip/journal/apl/105/3?ver=pdfcov

Published by the AIP Publishing

\section{Articles you may be interested in}

Excellent c-Si surface passivation by low-temperature atomic layer deposited titanium oxide

Appl. Phys. Lett. 104, 253903 (2014); 10.1063/1.4885096

Surface passivation of nano-textured silicon solar cells by atomic layer deposited Al2O3 films

J. Appl. Phys. 114, 174301 (2013); 10.1063/1.4828732

Extremely low surface recombination velocities in black silicon passivated by atomic layer deposition Appl. Phys. Lett. 100, 191603 (2012); 10.1063/1.4714546

Modulation of atomic-layer-deposited Al2O3 film passivation of silicon surface by rapid thermal processing Appl. Phys. Lett. 99, 052103 (2011); 10.1063/1.3616145

Zn ( O , S ) buffer layers by atomic layer deposition in $\mathrm{Cu}$ ( In , Ga ) Se 2 based thin film solar cells: Band alignment and sulfur gradient

J. Appl. Phys. 100, 044506 (2006); 10.1063/1.2222067

You don't

still use this

cell phone

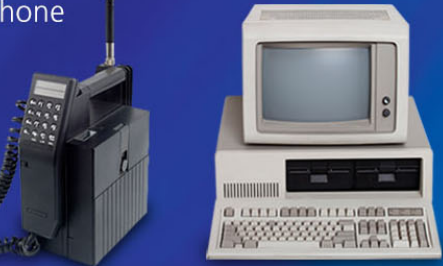

Why are you still using an AFM designed in the 80 's?
It is time to upgrade your AFM

Minimum \$20,000 trade-in discount for purchases before August 31st

Asylum Research is today's technology leader in AFM 


\title{
Electronic passivation of silicon surfaces by thin films of atomic layer deposited gallium oxide
}

\author{
T. G. Allen a) and A. Cuevas \\ Research School of Engineering, Australian National University, Canberra 0200, Australia
}

(Received 8 June 2014; accepted 1 July 2014; published online 21 July 2014)

\begin{abstract}
This paper proposes the application of gallium oxide $\left(\mathrm{Ga}_{2} \mathrm{O}_{3}\right)$ thin films to crystalline silicon solar cells. Effective passivation of $\mathrm{n}$ - and p-type crystalline silicon surfaces has been achieved by the application of very thin $\mathrm{Ga}_{2} \mathrm{O}_{3}$ films prepared by atomic layer deposition using trimethylgallium (TMGa) and ozone $\left(\mathrm{O}_{3}\right)$ as the reactants. Surface recombination velocities as low as $6.1 \mathrm{~cm} / \mathrm{s}$ have been recorded with films less than $4.5 \mathrm{~nm}$ thick. A range of deposition parameters has been explored, with growth rates of approximately $0.2 \AA /$ cycle providing optimum passivation. The thermal activation energy for passivation of the $\mathrm{Si}-\mathrm{Ga}_{2} \mathrm{O}_{3}$ interface has been found to be approximately $0.5 \mathrm{eV}$. Depassivation of the interface was observed for prolonged annealing at increased temperatures. The activation energy for depassivation was measured to be $1.9 \mathrm{eV}$. (C) 2014 AIP Publishing LLC. [http://dx.doi.org/10.1063/1.4890737]
\end{abstract}

Recombination of charge carriers at the silicon surface, especially beneath the metallised contact regions, remains one of the biggest loss mechanisms in crystalline silicon (c-Si) solar cells. ${ }^{1}$ An array of dielectric materials have been utilised for their capacity to suppress such defect-assisted Shockley-Read-Hall recombination, most notably silicon dioxide $\left(\mathrm{SiO}_{2}\right)$, silicon nitride, hydrogenated amorphous silicon (a-Si:H), and aluminium oxide $\left(\mathrm{Al}_{2} \mathrm{O}_{3}\right)$. Other dielectrics, like hafnium oxide and amorphous silicon carbide, have also been shown to provide chemical and chargeinduced passivation of recombination active surface states.

Gallium oxide $\left(\mathrm{Ga}_{2} \mathrm{O}_{3}\right)$ is a wide bandgap $\left(\mathrm{E}_{\mathrm{g}} \approx 4.23\right.$ $-5.24 \mathrm{eV})$, optically transparent semiconductor. ${ }^{2}$ Though typically non-conductive in its stoichiometric form, $\mathrm{Ga}_{2} \mathrm{O}_{3}$ can be doped with either silicon or tin for n-type conductivity. ${ }^{3}$ Gallium, like aluminium, is also a p-type dopant in silicon, and so $\mathrm{Ga}_{2} \mathrm{O}_{3}$ has the potential to be used as a p-type dopant source via thermal diffusion or laser processing. Additionally, the energy band structure of $\mathrm{Ga}_{2} \mathrm{O}_{3}$ suggests that it could be utilised as a carrier-selective contact to crystalline silicon. ${ }^{4}$

These properties have prompted research into the application of $\mathrm{Ga}_{2} \mathrm{O}_{3}$ to photovoltaics. Chandiran et al. ${ }^{5}$ have applied $\mathrm{Ga}_{2} \mathrm{O}_{3}$ to a dye-sensitized solar cell as an electron tunnelling interlayer between the porous, electron-collecting $\mathrm{TiO}_{2}$ layer, and the absorbing dye. The application of $\mathrm{Ga}_{2} \mathrm{O}_{3}$ reduced the electron back reaction into the electrolyte, resulting in an increase in the open circuit voltage $\left(\mathrm{V}_{\mathrm{oc}}\right)$ of the device. Recently, both Minami et al. ${ }^{6}$ and Lee et al. ${ }^{7}$ used $\mathrm{Ga}_{2} \mathrm{O}_{3}$ as a buffer layer between the p-type $\mathrm{Cu}_{2} \mathrm{O}$ and electron collecting $\mathrm{ZnO}: \mathrm{Al}$ in cupric-based heterojunction thin film solar cells. The application of the $\mathrm{Ga}_{2} \mathrm{O}_{3}$ buffer layer to the cupric-AZO interface reduced the recombination of charge carriers while permitting electron transfer to the negative terminal of the device, thereby enhancing $\mathrm{V}_{\mathrm{oc}}$.

\footnotetext{
${ }^{\text {a) }}$ Author to whom correspondence should be addressed. Electronic mail: thomas.allen@anu.edu.au
}

Despite these demonstrated qualities, and gallium oxide's known ability to passivate $\mathrm{GaAs}^{8}$ and reduce the density of surface defects in strained silicon, ${ }^{9}$ no attempt has yet been made to study this material on c-Si for photovoltaic applications. In this Letter, we provide evidence of surface passivation of crystalline silicon by $\mathrm{Ga}_{2} \mathrm{O}_{3}$ prepared by atomic layer deposition (ALD).

$\mathrm{Ga}_{2} \mathrm{O}_{3}$ thin films were prepared by ALD on $4-5 \Omega \mathrm{cm}$ n-type and 2-3 $\Omega \mathrm{cm}$ p-type FZ $\langle 100\rangle$ silicon in a Beneq TFS 200 ALD reactor with trimethylgallium (TMGa) and ozone $\left(\mathrm{O}_{3}\right)$ used as the reactants. A $200 \mu$ m diameter orifice was installed between the precursor and reactor to limit the precursor dose. All of the silicon samples were saw-damage etched in TMAH, cleaned in the standard RCA process, and immersed in a dilute HF solution prior to deposition. Variable angle spectroscopic ellipsometry (J.A. Woolam M2000D) was performed on polished samples that were also immersed in HF prior to $\mathrm{Ga}_{2} \mathrm{O}_{3}$ deposition in order to measure the thickness of the deposited films. A Tauc-Lorentz model was used to fit the ellipsometry data.

The effective minority carrier lifetime $\left(\tau_{e f f}\right)$ was measured as a function of the excess carrier concentration $(\Delta n)$ on symmetrically deposited lifetime structures using a Sinton Instruments WCT-120 photoconductance tool operating in the photoconductance decay (PCD) transient mode for the annealed samples, and in the quasi-steady-state (QSS) generalized mode for the as-deposited samples. All lifetime samples have been annealed in a forming gas ambient composed of $5 \% \mathrm{H}_{2} / 95 \% \mathrm{Ar}$ after initial comparisons with $\mathrm{N}_{2}$ annealing resulted in a considerable improvement in $\tau_{\text {eff. }}$.

Figure 1 plots the as-deposited $\mathrm{Ga}_{2} \mathrm{O}_{3}$ film thickness and post-anneal $\left(400{ }^{\circ} \mathrm{C}\right.$ for $15 \mathrm{~min}$ in forming gas) $\tau_{\text {eff }}$ against deposition temperature. All depositions comprised 200 ALD cycles. The range in deposition rate $(0.13-0.62 \AA /$ cycle $)$ is slightly greater than that reported by Comstock and Elam $\left(0.2-0.5 \AA /\right.$ cycle) over the same temperature range. ${ }^{10}$ From Figure 1, an observable optimum deposition temperature window for surface passivation exists between 200 and $250^{\circ} \mathrm{C}$ with the maximum in minority carrier lifetime 


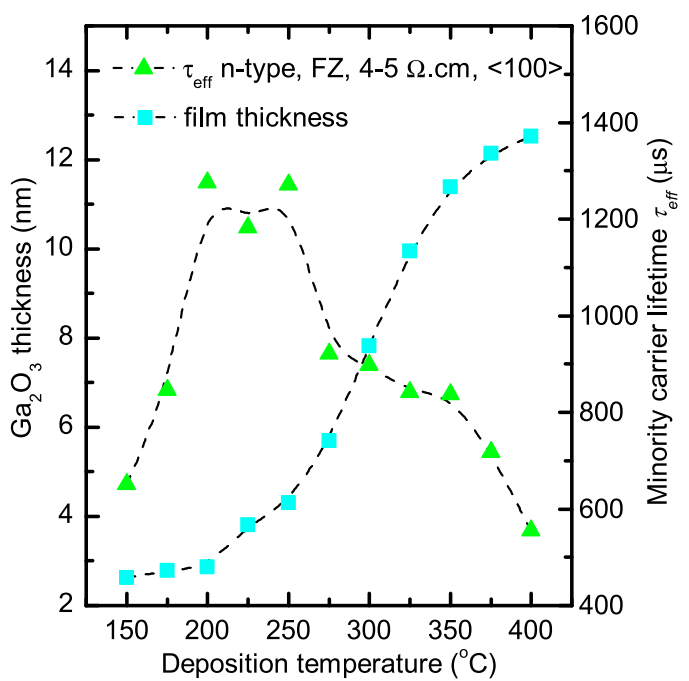

FIG. 1. As-deposited $\mathrm{Ga}_{2} \mathrm{O}_{3}$ film thickness and post-anneal minority carrier lifetime $\left(\tau_{\text {eff }}\right)$ on 4-5 $\Omega \mathrm{cm}$ n-type silicon plotted as a function of deposition temperature. All depositions comprised 200 ALD cycles. The lines serve as guides for the eyes.

corresponding to $\mathrm{Ga}_{2} \mathrm{O}_{3}$ films as thin as $2.85 \mathrm{~nm}$. The deposition rate in this window ranges from 0.14 to $0.22 \AA /$ cycle, approximately a quarter of the deposition rate at $400^{\circ} \mathrm{C}$ $\left(0.63 \AA /\right.$ cycle) and much lower than $\mathrm{ALD}_{2} \mathrm{Al}_{3}$ using TMA at similar temperatures (approximately $1-1.5 \AA$ /cycle). Donmez et al. have reported a steadier growth rate using TMGa and $\mathrm{O}_{2}$ plasma with a temperature-independent growth rate of $0.53 \AA$ /cycle reported in the deposition window of $100-400{ }^{\circ} \mathrm{C}^{11}$ Dezlah et al. also report on atomic layer deposited $\mathrm{Ga}_{2} \mathrm{O}_{3}$ with $\mathrm{Ga}_{2}\left(\mathrm{NMe}_{2}\right)_{6}$ and $\mathrm{H}_{2} \mathrm{O}$ with growth rates in excess of $1 \AA /$ cycle for deposition temperatures between 150 and $250^{\circ} \mathrm{C}$ : similar to TMA- $\mathrm{H}_{2} \mathrm{O} \mathrm{Al}{ }_{2} \mathrm{O}_{3}$ thermal ALD deposition rates. ${ }^{12}$

A deposition temperature of $250^{\circ} \mathrm{C}$ was used for further study of the annealing parameters because of its favourable initial passivation results and growth rate. Float zone, $4-5 \Omega$ $\mathrm{cm}$ n-type samples deposited at $250{ }^{\circ} \mathrm{C}$ were annealed in forming gas at a range of temperatures between 300 and $450{ }^{\circ} \mathrm{C}$ in order to derive the optimum anneal conditions. The results are plotted in Figure 2.

The $x$-axis in Figure 2 denotes the cumulative anneal time $t_{a n}$ for a double-side deposited sample; the $y$-axis represents the $\tau_{\text {eff }}$ measured at an injection level of $\Delta n=1 \times 10^{15}$ $\mathrm{cm}^{-3}$. The optimum annealing condition-180 $\mathrm{min}$ at $350^{\circ} \mathrm{C}$-resulted in a minority carrier lifetime of approximately $2.5 \mathrm{~ms}$ and an upper limit to the surface recombination velocity (SRV) of $6.1 \mathrm{~cm} / \mathrm{s}$, where the Auger parameterization of Richter et al. ${ }^{13}$ was used to calculate the bulk lifetime. This compares to a $\tau_{\text {eff }}$ of $9.5 \mathrm{~ms}$ and an SRV of $1.5 \mathrm{~cm} / \mathrm{s}$ for a similar sample passivated with $20 \mathrm{~nm}$ of plasma-assisted $\mathrm{ALD} \mathrm{Al}_{2} \mathrm{O}_{3}$ and annealed in forming gas for 30 min at $425^{\circ} \mathrm{C}$. Spatially resolved $\tau_{\text {eff }}$ maps for both $\mathrm{n}$ - and p-type $\mathrm{Ga}_{2} \mathrm{O}_{3}$ passivated samples are displayed in Figure 3 .

From Figure 2, it is evident that the rate of activation of the passivation is increasing with temperature. The optimum annealing time $\left(t_{a n}\right)$ for each annealing temperature $\left(T_{a n}\right)$ also results in an increase in the maximum observed $\tau_{\text {eff }}$ as $T_{a n}$ decreases, with the exception of $T_{a n}=300{ }^{\circ} \mathrm{C}$ where a

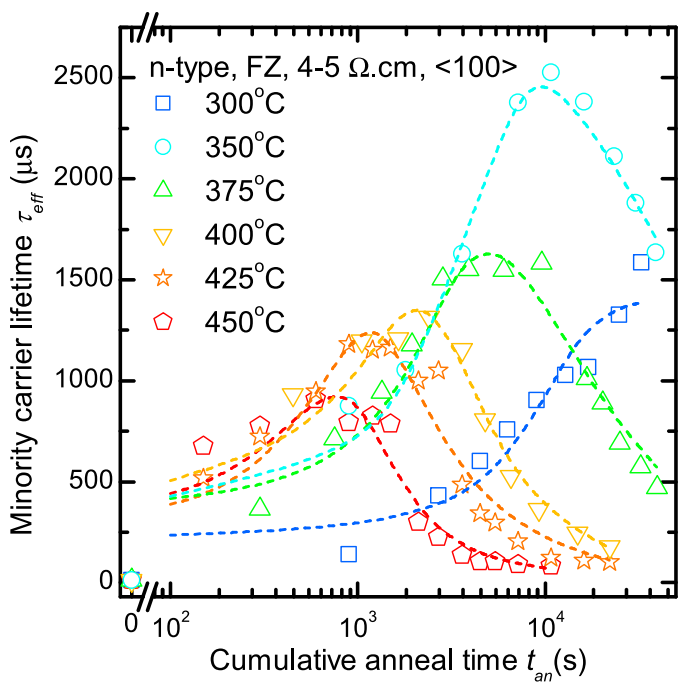

FIG. 2. Minority carrier lifetime as a function of cumulative annealing time. The dashed curves represent the modelled data using Eq. (1). The asdeposited data are shown at $t_{a n}=0$.

maximum in $\tau_{\text {eff }}$ had not been reached after over 9 hours of annealing. A similar effect is observable for the reverse, depassivation reaction for temperatures greater than $300^{\circ} \mathrm{C}$ : as the annealing temperature increases, the rate at which the interface depassivates also increases. After the initial activation of the passivation, the lifetime decreases to an equilibrium value (approximately $100 \mu \mathrm{s}$ ), greater than the as-deposited lifetime (approximately $10 \mu \mathrm{s}$ ), indicating that some passivation of the interface is retained.

An exponential model has been applied to fit the $\tau_{e f f}\left(t_{a n}, T_{a n}\right)$ data to further analyse the passivation and depassivation reactions. The model is based on that of Mitchell et al., who applied an exponential fit to temperature and time dependent $\tau_{\text {eff }}$ data from a-Si:H-passivated silicon surfaces, ${ }^{14}$ and Dingemans et al., who applied the same model to $\mathrm{SiO}_{2}-$ $\mathrm{Al}_{2} \mathrm{O}_{3}$ stacks on $\mathrm{c}-\mathrm{Si}^{15}$ The exponential model has been extended to account for both the passivation and depassivation of the $\mathrm{Si}_{-}-\mathrm{Ga}_{2} \mathrm{O}_{3}$ interface

$$
\begin{aligned}
\frac{1}{\tau_{\text {eff }}}= & {\left[a+b \exp \left(-t_{\text {an }} / R_{\text {pass }}\right)\right] } \\
& +\left[c-d \exp \left(-t_{\text {an }} / R_{\text {depass }}\right)\right],
\end{aligned}
$$

where the first bracketed term represents the exponential fitting to the passivation data, and the second bracketed term represents the exponential decay associated with the depassivation data. The parameters $R_{\text {pass }}$ and $R_{\text {depass }}$ are the time constants of the passivation and depassivation reactions. These reaction time constants are then used to extract the activation energies for both the passivation and depassivation reactions according to the Arrhenius equation

$$
R_{(d e) p a s s}=A \exp \left(-\frac{E_{A}}{k_{B} T_{a n}}\right) .
$$

The dashed curves in Figure 2 represent the summed exponential model of Eq. (1) applied to the measured values of $\tau_{\text {eff. }}$ The divergence of the model from the data in Figure 2 can be ascribed to a number of factors. The use of a single 

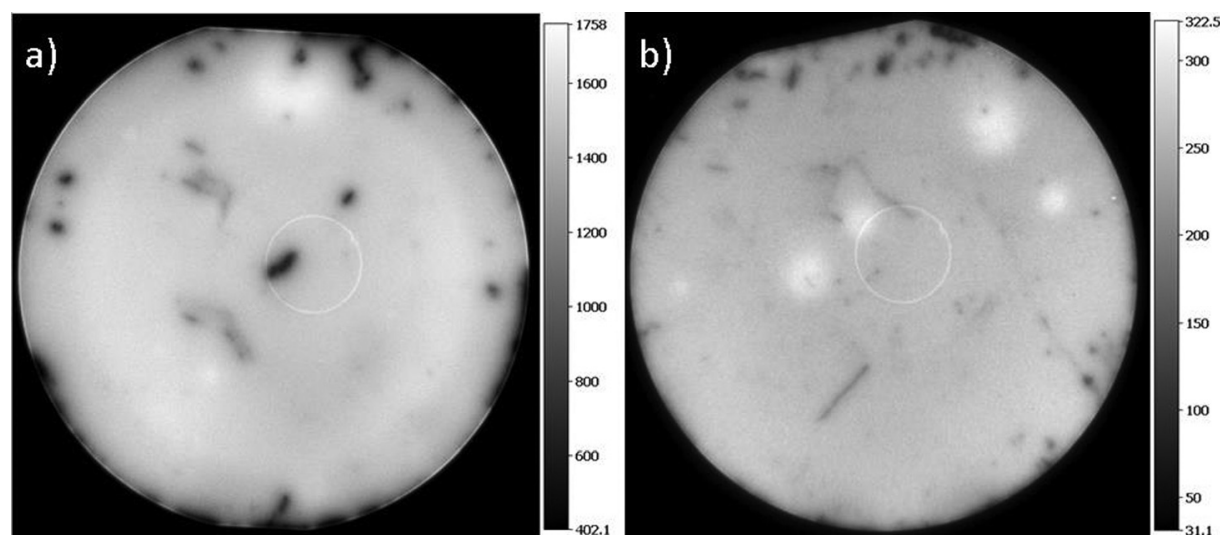

FIG. 3. Spatially resolved minority carrier lifetime maps from PL images of (a) $\mathrm{Ga}_{2} \mathrm{O}_{3}$-passivated 4-5 $\Omega \mathrm{cm} \mathrm{n}$ type and (b) 2-3 $\Omega \mathrm{cm}$ p-type silicon, both annealed at $375^{\circ} \mathrm{C}$ for $50 \mathrm{~min}$ in forming gas. The images reveal a uniform passivation across the wafer surface. Note the difference in scale between the two images.

sample for each $T_{a n}$ study introduces some uncertainty in $\tau_{\text {eff }}$, resulting in an artificial stretching of the curves along the $x$-axis and compression in the $y$-axis. Also, if the mechanism for passivation involves the interaction with another chemical species (hydrogen, for example, is commonly identified as a passivating mechanism for surface defects in crystalline silicon ${ }^{14-17}$ ), then the availability of that species is not accounted for in the model. The results, for example, are consistent with the progressive effusion of hydrogen from the $\mathrm{Si}-\mathrm{Ga}_{2} \mathrm{O}_{3}$ interface with increasing annealing temperature and time after the observed peak in $\tau_{\text {eff. }}$ This hypothesis of a reaction mechanism that involves a limited and diminishing source of one species may also account for the better fitting of the model to the data for annealing times after the peak in passivation is achieved. Despite these possible limitations, the model does provide a reasonable fit to the lifetime data.

The Arrhenius plots of Figure 4 display the extracted reaction time constants of Eq. (1) as a function of inverse energy. The plotted symbols in Figure 4 give the best fits to both the $\tau_{\text {eff }}$ data and the Arrhenius model of Eq. (2). The error bars in the plot represent the upper and lower bounds in reaction rate values that still give a credible fit to the data in

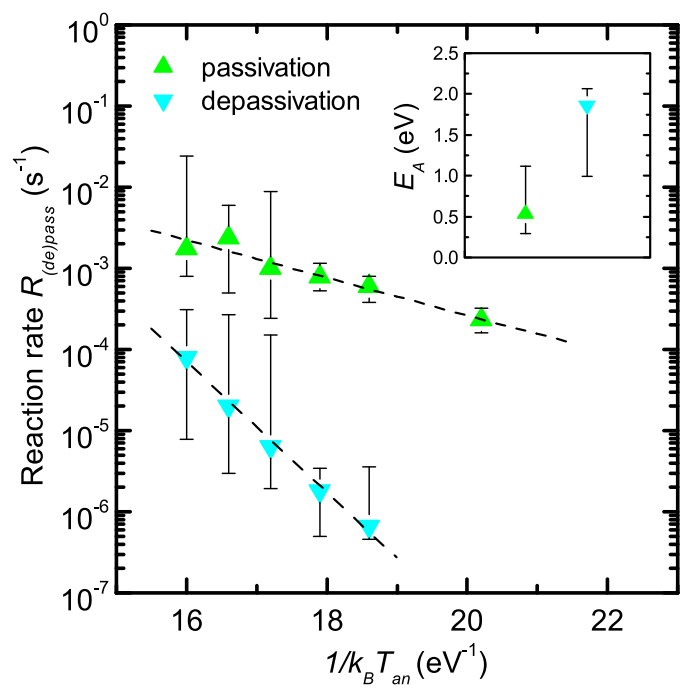

FIG. 4. Arrhenius plot of the reaction rate $\left(R_{\text {(de)pass }}\right)$ extracted from Eq. (1). The error bars in $R$ represent the upper and lower bounds in reaction rate values that give a credible fit to the data in Figure 2. The error bars in the extracted activation energies are the values of $E_{A}$ extracted from the bounds in possible $R$ values.
Figure 2, and so they are not directly representative of the error in the reaction rate, which is difficult to quantify given the reasons outlined in the discussion above.

The application of Eq. (2) to the reaction rates of Eq. (1) indicates an activation energy $E_{A}$ of approximately $0.5 \mathrm{eV}$ for the passivation reaction and $1.9 \mathrm{eV}$ for the depassivation reaction. The error bars in the inset graph of $E_{A}$ in Figure 4 correspond to the activation energies extracted from the error bar values for the reaction rates. Therefore, they are not indicative of the error in the fits of Eq. (2) to the plotted data in the figure, which is small, but rather represent a range of possible, albeit less likely, values for $E_{A}$.

The approximate activation energy for passivation extracted from the data in Figure $4(0.5 \mathrm{eV})$ is similar to the values reported by Mitchell et al. ${ }^{14}(0.67 \mathrm{eV})$ and de Wolf and Kondo $^{16}(0.6 \mathrm{eV})$ for the activation of a-Si:H; and outside the range reported by Richter et al. ${ }^{17}(1.4-1.5 \mathrm{eV})$ and Saint-Cast ${ }^{18}(1.5 \mathrm{eV})$ for $\mathrm{Al}_{2} \mathrm{O}_{3}$ films, and Dingemans et $a{ }^{15}{ }^{15}(0.9$ and $1.2 \mathrm{eV})$ for $\mathrm{Al}_{2} \mathrm{O}_{3}-\mathrm{SiO}_{2}$ stacks. Mitchell et al. suggest that the lower activation energies for a-Si:H indicate an interfacial hydrogen dependency on passivation, rather than a bulk hydrogen effusion process. ${ }^{14}$ Conversely, Richter et al. claim that the higher activation energy for $\mathrm{Al}_{2} \mathrm{O}_{3}$ passivation relates to both the existence of an interfacial $\mathrm{SiO}_{2}$ layer, citing the similar activation energy of Stesmans ${ }^{19}$ for the $\mathrm{Si}-\mathrm{SiO}_{2}$ interface, and the diffusion of hydrogen from the bulk of the $\mathrm{Al}_{2} \mathrm{O}_{3}$ film. The diffusion of bulk hydrogen from $\mathrm{Al}_{2} \mathrm{O}_{3}$ films to passivate the $\mathrm{Si}-\mathrm{SiO}_{2}$ interface is further demonstrated in Ref. 15. Richter et al. further attribute the passivation of the interface to structural changes in the $\mathrm{Al}_{2} \mathrm{O}_{3}$ film which could be a factor in the annealing behaviour of the $\mathrm{Ga}_{2} \mathrm{O}_{3}$ films. ${ }^{17}$

For the $\mathrm{Ga}_{2} \mathrm{O}_{3}$ passivation studied in this work, uncertainty in $E_{A}$ and the as-yet unknown properties of the material itself, compared to the other films studied using this technique, does not support such strong conclusions regarding the nature of the passivation mechanism. What can be concluded from the data is that the difference in the passivation and depassivation activation energies is not as great as for a-Si:H, $\mathrm{Al}_{2} \mathrm{O}_{3}$ or $\mathrm{SiO}_{2}$ passivation dielectrics. This could have implications relating to the stability of the passivation, and for the potential thermal processing windows if $\mathrm{Ga}_{2} \mathrm{O}_{3}$ were to be incorporated into a photovoltaic device.

Very thin films of ALD deposited gallium oxide $\left(\mathrm{Ga}_{2} \mathrm{O}_{3}\right)$ have been shown to effectively passivate $\mathrm{n}$ - and p-type silicon surfaces, with an optimum post-deposition 
annealing condition $\left(350^{\circ} \mathrm{C}\right.$ for $\left.180 \mathrm{~min}\right)$ resulting in a minority carrier lifetime of $2.5 \mathrm{~ms}$ on $4-5 \Omega \mathrm{cm}$ n-type silicon. Photoluminscence (PL) imaging of the passivated wafers show a uniformity in passivation across the 4 in. wafer surface. The annealing temperature and time dependence of $\tau_{\text {eff }}$ have been modelled using a sum of two exponentials in order to calculate the activation energies for the passivation and depassivation reactions: approximately 0.5 and $1.9 \mathrm{eV}$, respectively.

The authors would like to thank Dr. D. Macdonald for his many suggestions and help in preparing the manuscript. This work has been supported by the Australian government through the Australian Renewable Energy Agency (ARENA). Ellipsometer facilities at the Australian National Fabrication Facility were used in this work.

${ }^{1}$ R. M. Swanson, in Proceedings of the 31 st IEEE Photovoltaic Specialists Conference, 2005.

${ }^{2}$ F. K. Shan, G. X. Liu, W. J. Lee, G. H. Lee, I. S. Kim, and B. C. Shin, J. Appl. Phys. 98, 023504 (2005).

${ }^{3}$ S. Ohira, N. Suzuki, N. Arai, M. Tanaka, T. Sugawara, K. Nakajima, and T. Shishido, Thin Solid Films 516, 5763 (2008).
${ }^{4}$ J. Robertson, Thin Solid Films 516, 1419 (2008).

${ }^{5}$ A. K. Chandiran, N. Tetreault, R. Humphry-Baker, F. Kessler, E. Baranoff, C. Yi, M. K. Nazeeruddin, and M. Grätzel, Nano Lett. 12, 3941 (2012).

${ }^{6}$ T. Minami, T. Miyata, and Y. Nishi, Sol. Energy 105, 206 (2014).

${ }^{7}$ Y. S. Lee, D. Chua, R. E. Brandt, S. C. Siah, J. V. Li, J. P. Mailoa, S. W. Lee, R. G. Gordon, and T. Buonassisi, Adv. Mater. 26(27), 4704-4710 (2014).

${ }^{8}$ M. Passlack, M. Hong, E. F. Schubert, J. R. Kwo, J. P. Mannaerts, S. N. G. Chu, N. Moriya, and F. A. Thiel, Appl. Phys. Lett. 66, 625 (1995).

${ }^{9}$ S. Pal, S. K. Ray, B. R. Chakraborty, S. K. Lahiri, and D. N. Bose, J. Appl. Phys. 90, 4103 (2001).

${ }^{10}$ D. J. Comstock and J. W. Elam, Chem. Mater. 24, 4011 (2012).

${ }^{11}$ I. Donmez, C. Ozgit-Akgun, and N. Biyikli, J. Vac. Sci. Technol., A 31, $01 \mathrm{~A} 110$ (2013).

${ }^{12}$ C. L. Dezlah IV, J. Niinisto, K. Arstila, L. Niinisto, and C. H. Winter, Chem. Mater. 18, 471 (2006).

${ }^{13}$ A. Richter, S. W. Glunz, F. Werner, J. Schmidt, and A. Cuevas, Phys. Rev. B 86, 165202 (2012).

${ }^{14}$ J. Mitchell, D. Macdonald, and A. Cuevas, Appl. Phys. Lett. 94, 162102 (2009).

${ }^{15}$ G. Dingemans, F. Einsele, W. Beyer, M. C. M. van de Sanden, and W. M. M. Kessels, J. Appl. Phys. 111, 093713 (2012).

${ }^{16}$ S. de Wolf and M. Kondo, Appl. Phys. Lett. 90, 042111 (2007).

${ }^{17}$ A. Richter, J. Benick, M. Hermle, and S. W. Glunz, Appl. Phys. Lett. 104, 061606 (2014).

${ }^{18}$ P. Saint-Cast, Ph.D. dissertation, University of Konstanz, 2012.

${ }^{19}$ A. Stesmans, Appl. Phys. Lett. 68, 2076 (1996). 